\title{
"A STUDY ON SAURA TRIBE WOMEN EMPOWERMENT GAJAPATI, RAYGADA \& GANJAM DISTRICT ODISHA ”
}

\author{
${ }^{1}$ Pravat Kumar Ghadei, ${ }^{2}$ Dr.Santosh Salve \\ ${ }^{1}$ UG - Research. Scholar, Social Work, Madhyanchal Professional University, Bhopal [M.P.] \\ ${ }^{2}$ Professors, Department of Arts. Social Science \& Humanity, Madhyanchal Professional University, Bhopal [M.P.]
}

\begin{abstract}
A tribe is a social group with territorial affiliation, endogamous, with no specialization of function ruled by tribal, hereditary or otherwise, united in language or dialect, recognising social distance with other tribes, caste, without any social obloquy attaching to them as it does in the caste structure following tribal traditions, belief and customs illiberal, A tribe is a group of people, usually staying in jungle areas, in a small locality, absolutely illiterate poor, hardly clad in clothes, usually dark and frail, fully living within their own community whose marriage always takes place among themselves, engaged in hunting and searching for roots, shoots and fruits as their veg food and roasted animals as non-veg food, completely oblivious of the country's political and economic condition,

Women are the part of our society. They are equal like a man, under Saoura tribe women are depend on man, they are restricted some of religious decision. They play a role for help to man for farming. Cultivation, other activity like Goat rearing, collective of Forts production, like seali leaf, Honey, etc, Most of farming production like Raghi, paddy, ginger, Turmeric, Lakha, wild honey are the main shores of livelihood.
\end{abstract}

Keywords: women are the play main role decision making

\section{INTRODUCTION}

In contemporary India, the word tribe 'has thus little cultural or social implications. It has become the watchword of the political consciousness of a particular group of a people in the country. Like caste consciousness or regional consciousness, tribal consciousness is fast developing to be a political tool which has become symbolic of privileged treatment, separatist tendencies and in places a barrier to national integration. The tribal as man is simple, humble and possesses a great amount of feeling for his co-villagers and kings man in particular and community members in general. They grow in the intimacy of the social atmosphere of his community. His close association with nature inspires him to lead a carefree life. They feel pleasure in roaming about hills, forests and fields. Nature makes him intimate with the environment. He often meets friends and visits his own relations on different festive occasions and in periodical new relations and association with people. Purely for sake of classification and enumeration, the British Government in India introduced the category of tribe'(with occasional qualifying prefixes like hill and jungle aboriginal indigenous') to designate these people.

\section{2-STATUS OF TRIBAL WOMEN:-}

The tribal women, constitute like any other social group, about half of the total population. The tribal women, as women in all social groups, are more illiterate than men. Like others social groups, the tribal women share problems related to reproductive health. When primary and secondary subsistence activities are counted, women work more than men. Status of women varies in different societies. The conceptual framework to analyse women's status comprise the seven roles women play in life and work: - parental, conjugal, domestic, kin, occupational, community and as an individual. In order to appraise the social status of women in these diverse ecological areas, the findings have been divided in to subsequent categories: - (a) a girl; daughter; a unmarried woman; (b) a married woman; (c) a widow; (d) divorcee; and (e) a barren woman. Role of women is not only of importance in economic activities, but her role in noneconomic activities is equally important. The tribal women work very hard, in some cases even more than the men. All the tribal societies in the study area are patriarchal in which men dominate in public sector. However, in their own world women have a freedom, and a self-expression. With the onset of development programmes economic changes are taking place but tribal women remain traditional in their dress, language, tools and resources, because they grow food crops rather than cash crops. Modernisation is bringing changes, which affect men and women differently. India as a whole is characterised by sharp gender disparities, although women's status varies considerably by region. On virtually 


\section{International Advanced Research Journal in Science, Engineering and Technology \\ Impact Factor $7.105 \div$ Vol. 9, Issue 1, January 2022 \\ DOI: 10.17148/IARJSET.2022.9157}

all frontiers of human societal pursuits-economic, educational, scientific, legal, political, official, political and religious sphere Indian women suffer profoundly. For all time there are socio-cultural factors, which validate for the status of women in particular society. It is always culture (a set of collective experiences of ideas, norms, values and beliefs associated with a people) with its gender role inequalities and socialisation (the intricate process through which culture is transmitted from one generation to another) determines the position of women in a society. Gender roles are socially constructed. The family structure in India is patriarchal, patrilocal and patrilineal. Patriarchy denotes a culture of power relationship that promotes man's supremacy and women subjugation. It encompasses institutional endorsement of man's ascendancy within the family and other social structures. It justifies the normative process pertaining to the recognition and sustainability of his dominance in society. Consequently a boy is looked upon as the perpetuator of the family line, and a girl 'a bird of passage'. The Indian family organisation makes discrimination between the sexes. It promotes a hierarchy of classification in which man centred issues take dominance where as women derive their personalities from their fathers', husbands', brothers' and sons. With a secondary status, women play but a submissive role in social life. Despite several economic, political and social changes, women, are still far behind. One of the most unflattering statistics concerning India's girl child shows that the preference for a son runs across rich as well as poor households, educated as well as illiterate families. Widespread use of modern technology, a joint failure of medical ethics and failure to shed concept of a male heir has pushed female foeticide to high proportions. Female foeticide is just one side of the vast anti-women behavioural range in India. The tragedy is that even women, who have the choice, opt for a male child. They feel that only with a birth of a son, they will achieve higher status.

\section{3 . ABOUT INDIAN TRIBE:-}

Tribes of India: Definition of Tribe One of the major issues in tribal studies today, and it is clear from the draft as well, pertains to the "definition" of "tribe" (from now on, whenever the term draft is used, it refers to its second version). Many of us think that since we are concerned with communities of people classified as scheduled tribes (STs) and there is less ambiguity about this term, although some communities classified so may not deserve the appellation of tribe, not much will be gained by getting bogged down into the ever-polemical and inconclusive issues of the definition. As per this argument, our concern is with the "scheduled tribes", and not with "tribes"; the former category includes about 700 communities, according to the draft, which notwithstanding their inter-cultural differences share the same relation of deprivation with respect to nontribal people. The other view is that in India, the continuities between tribes and castes are so much that it often becomes difficult to distinguish (or separate) one from the other. Not only is this the experience of contemporary students of tribal societies, but was also of the census enumerators in the late 19th century. Often, communities were arbitrarily listed as tribes (or castes), and this decision was left to the perception of the local community by the individual enumerator. There have been cases of communities classified as tribes in one state and as castes in another. Tribes and Castes: Identities

The presence of the continuities between tribes and castes did not imply that there were no differences between them. The differences existed, and there were "real communities" that approximated (and, in same cases, were the ideal types of) the textbook definition of tribe. However, a large number of communities, classified as "tribal", dwelt in close proximity to "caste" communities, having long-standing relations of exchange with them. These relations have obviously contributed towards a myriad of similarities between them, thus bringing castes and tribes closer, leading to a deviation of both the social formations from their ideal definitions. The important point, however, is that albeit these similarities, the tribes have tried to maintain their respective identities, and so do castes. The conclusion from this observation is that it is not a worthless exercise to think in terms of the social and cultural indices that constitute a tribe in relationship to a caste. The blurring of the social categories does not imply their complete merging. Tribes and castes constituting as two types of the social formation is still a relevant point of departure to understand contemporary India, and therefore the matter of definition should not be skirted. The draft notes that the criteria the Lokur Committee has evolved for declaring a particular community as a ST are: (i) an ensemble of primitive traits, (ii) distinctive culture, (iii) geographical isolation, (iv) shyness of contact with the outside world, and (v) backwardness. Immediately after delineating them, the draft notices that "even all these broad criteria are not applicable to Scheduled Tribes today" ( $\mathrm{p} 2$ ). On page 21, it says: "The criteria laid down by the Lokur Committee are hardly relevant today. For instance, very few tribes can today be said to possess 'primitive traits' (Vinay Kumar Srivastava, 2008) ."

4-Methodology

This paper describes an exploratory study in Rayagada, Gajapati District of Odisha which aimed to understand tribal women's experiences livelihood farming concept it also study pregnancy and childbirth and their interactions with the formal health system. Methods included in-depth interviews with women, traditional healers and formal health care providers and outreach workers, observations in the community and health facilities.

Social work research means conducting an investigation in accordance with the scientific method. The aim of social work research is to build the social work knowledge base in order to solve practical problems in social work practice or social policy. Investigating phenomena in accordance with the scientific method requires maximal adherence to 


\section{International Advanced Research Journal in Science, Engineering and Technology \\ Impact Factor $7.105 \div$ Vol. 9, Issue 1, January 2022 \\ DOI: 10.17148/IARJSET.2022.9157}

empirical principles, such as basing conclusions on observations that have been gathered in a systematic, comprehensive, and objective fashion.

In this research we deeply understanding how the Tribal women are improved their livelihood, having self decision making power, improved the girls education, how the women are equal to male, so look out this study we used several method and tools technique for smoothly understanding among the sourer tribe women Empowerment,

Qualitative and Quantitative research method are provides a deep understanding of the problem in separate manner. Quantitative Research on the other hand focuses more in counting and classifying features and constructing statistical models and figures to explain what is observed Qualitative Research is ideal for earlier phases of research projects while for the latter part of the research project, Quantitative Research is highly recommended. Quantitative Research provides the researcher a clearer picture of what to expect in his research compared to Qualitative Research. Data Gathering Instrument

The researcher serves as the primary data gathering instrument in Qualitative Research. Here, the researcher employs various data-gathering strategies, depending upon the thrust or approach of his research. Examples of data-gathering strategies used in Qualitative Research are individual in-depth interviews, structured and non-structured interviews, focus groups, narratives, content or documentary analysis, participant observation and archival research. On the other hand, Quantitative Research makes use of tools such as questionnaires, surveys, measurements and other equipment to collect information at grassroots,

\subsection{Type of Data}

The presentation of data in a Qualitative Research is in the form of words interact the community people. Or direct interviews as like primary source of information, some of information like magazine, article, internet and Government department is the secondary data also help full to the researcher, as researcher conducting a Qualitative Research it's most likely appear in the discussion are figures in the form of graphs. However, if I as a researcher conducting a Quantitative Research, what will most likely appears in this discussion are tables containing data in the form of numbers and statistics.

\subsection{Approach}

Qualitative Research is primarily subjective in approach as it seeks to understand human behaviour and reasons that govern such behaviour. Researchers have the tendency to become subjectively immersed in the subject matter in this type of research method. In Quantitative Research, researchers tend to remain objectively separated from the subject matter. This is because Quantitative Research is objective in approach in the sense that it only seeks precise measurements and analysis of target concepts to answer his inquiry.

Sampling is a important part of research this is a small part who described the entire study and its output, in other word Sampling is the statistical process of selecting a subset (called a "sample") of a population of interest for purposes of making observations and statistical inferences about that population. Social science research is generally about inferring patterns of behaviors within specific populations. We cannot study entire populations because of feasibility and cost constraints, and hence, we must select a representative sample from the population of interest for observation and analysis. It is extremely important to choose a sample that is truly representative of the population so that the inferences derived from the sample can be generalized back to the population of interest. Improper and biased sampling is the primary reason for often divergent and erroneous inferences reported in opinion polls and exit polls etc.

It is used to appropriately select elements of a target population to create a sample group that is representative of the entire population. Researchers need sample groups to make inferences about a sample group that can be generalizable to the whole target population.

Researchers use different sampling methods depending on their resources, time limitations, research topic etc. Different methods of sampling are apt for different studies. In this article we will be discussing the types of sampling.

Non Probable sampling:-

The difference between nonprobability and probability sampling is that nonprobability sampling does not involve random selection and probability sampling does. Does that mean that nonprobability samples aren't representative of the population? Not necessarily. But it does mean that nonprobability samples cannot depend upon the rationale of probability theory. At least with a probabilistic sample, we know the odds or probability that we have represented the population well. We are able to estimate confidence intervals for the statistic. With nonprobability samples, we may or may not represent the population well, and it will often be hard for us to know how well we've done so. In general, researchers prefer probabilistic or random sampling methods over nonprobabilistic ones, and consider them to be more accurate and rigorous. However, in applied social research there may be circumstances where it is not feasible, practical or theoretically sensible to do random sampling. Here, we consider a wide range of nonprobabilistic alternatives.

We can divide nonprobability sampling methods into two broad types: accidental or purposive. Most sampling methods are purposive in nature because we usually approach the sampling problem with a specific plan in mind. The most 


\section{International Advanced Research Journal in Science, Engineering and Technology \\ Impact Factor $7.105 \div$ Vol. 9, Issue 1, January 2022 \\ DOI: 10.17148/IARJSET.2022.9157}

important distinctions among these types of sampling methods are the ones between the different types of purposive sampling approaches.

\subsection{Quota Sampling}

In quota sampling, you select people nonrandomly according to some fixed quota. There are two types of quota sampling: proportional and non proportional. In proportional quota sampling you want to represent the major characteristics of the population by sampling a proportional amount of each. For instance, if you know the population has $40 \%$ women and $60 \%$ men, and that you want a total sample size of 100 , you will continue sampling until you get those percentages and then you will stop. So, if you've already got the 40 women for your sample, but not the sixty men, you will continue to sample men but even if legitimate women respondents come along, you will not sample them because you have already "met your quota." The problem here (as in much purposive sampling) is that you have to decide the specific characteristics on which you will base the quota. Will it be by gender, age, education race, religion, etc.?

Nonproportional quota sampling is a bit less restrictive. In this method, you specify the minimum number of sampled units you want in each category. here, you're not concerned with having numbers that match the proportions in the population. Instead, you simply want to have enough to assure that you will be able to talk about even small groups in the population. This method is the nonprobabilistic analogue of stratified random sampling in that it is typically used to assure that smaller groups are adequately represented in your sample

4.4.Case study-

Case studies are in-depth investigations of a single person, group, event or community. Typically, data are gathered from a variety of sources and by using several different methods

The case study research method originated in clinical medicine (the case history, i.e. the patient's personal history). In psychology, case studies are often confined to the study of a particular individual.

The information is mainly biographical and relates to events in the individual's past (i.e. retrospective), as well as to significant events which are currently occurring in his or her everyday life.

The case study is not itself a research method, but researchers select methods of data collection and analysis that will generate material suitable for case studies.

\section{Study Area}

This study are focused South Odisha are three district like Ganjam, Gajapati and Rayagada. It's a part of Eastern Ghats range All district introconection as boundary each other having hill bases area,

\subsection{Geographical Distribution of Tribes}

Experiments / Analysis / Simulation

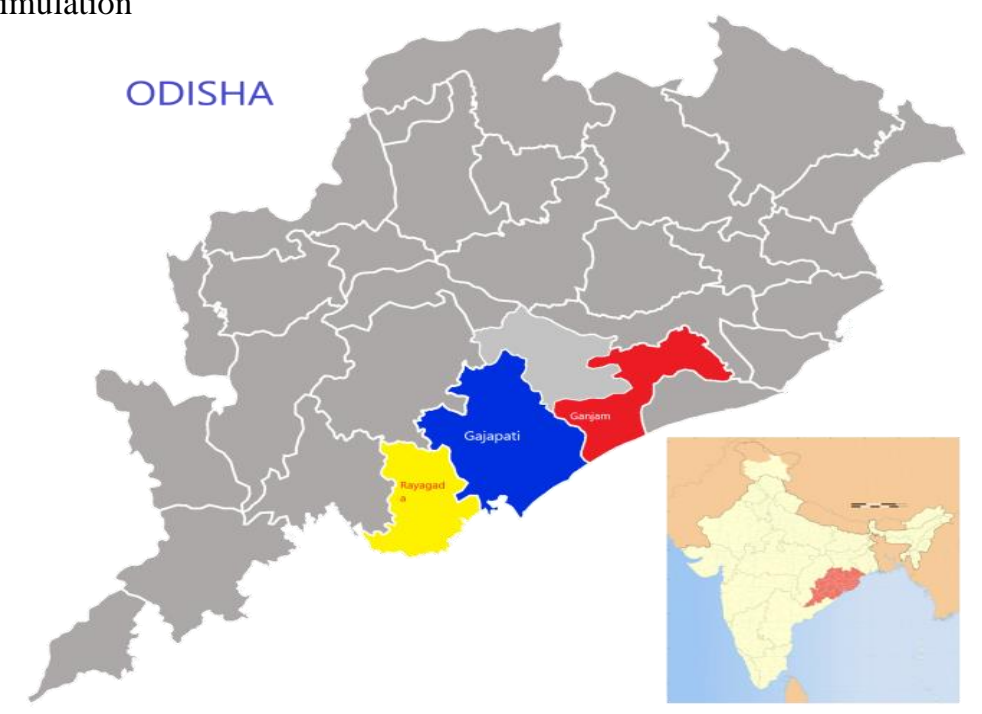

\section{Population of Three District Odisha}

\begin{tabular}{|l|l|l|l|l|l|}
\hline Sl no & Name of the District & Population & Male & Female & Female literacy \\
\hline 1 & Gajapati & 5.78 & 2828882 & 294935 & 43.81 \\
\hline 2 & Ganjam & 35.29 & 1779218 & 1749813 & 61.13 \\
\hline
\end{tabular}


International Advanced Research Journal in Science, Engineering and Technology

Impact Factor $7.105 \div$ Vol. 9, Issue 1, January 2022

DOI: 10.17148/IARJSET.2022.9157

\begin{tabular}{|l|l|l|l|l|l|}
\hline 3 & Rayagada & 9.68 & 471960 & 495951 & 31.19 \\
\hline
\end{tabular}

(source of information collection Censes report 2011 Govt of India)

\subsection{CONSTITUTIONAL SAFEGUARDS}

our constitution provides a number of provisions to ensure development and protection to tribal culture and society. The basic idea behind these was to ensure state support for less privileged actions of society. By providing reservations in legislatures and government jobs their participation in the affairs of the state was ensured. The constitutional provisions for the uplifiment of tribes,

II. Constitutional1 provisions of Tribal. The constitution has given more than 20 articles on the redressed and upliftment of underprivileged with policies on positive discrimination and affirmative action with reference to S.T. Article 14 confers equal rights and opportunities to all• Article 15 prohibits discrimination against any citizen on the grounds of sex, religion, race, caste etc; $\bullet$ Article 15 (4) States to make special provisions for advancement of any socially educationally backward• classes; Article 16 (4) empowers the state to make provisions for reservation in appointments or posts in favour of $\bullet$ any backward class of citizens, which in the opinion of state, is not adequately represented. Article 46 state to promote with special cares the educational and economic interests of the weaker section, $\bullet$ especially the ST and protects the social injustice and all form of exploitation. Article 275 grant-in aid for promoting the welfare of ST and raising the level of administration• Article 330 - Seats shall be reserved in the House of the People for Article 332 Reservation of seats for $\bullet$ Scheduled Castes and Scheduled Tribes in the Legislative Assemblies of the States 332,335 stipulates the claims that the members of the Scheduled Castes and the Scheduled Tribes shall be taken into consideration, consistently with the maintenance of efficiency of administration, in the making of appointments to services and posts in connection with the affairs of the Union or of a State. Article 244(1) tribal welfare communities to be setup for the welfare of the tribes. $\bullet$ Article 22(2) 73rd and 74th amendments - to ensure effective participation of tribal in the process of planning • and decision making. Extension to scheduled Areas Act 1996. Amendments of Constitution are extended to the Scheduled Areas $\bullet$ through Panchayats. These constitutional provisions of the Government of India helped in the development of the tribes and their education.

5.1.Socio-Economic Condition of Tribes:- in India The Socio-economic structure in tribal communities is markedly different from that of the non-tribals or advanced groups of people. They have a very simple technology which fits well with their ecological surroundings and conservative outlook. Moreover, their economy can be said to be subsistence type, they practice different types of occupations to sustain themselves and live on - Marginal Economy. The soura tribals belong to different economic stages, from food gathering, which present their overlapping economic stages in the broader frame work of the state economy. And the last important point to be emphasized is that a tribe is usually considered as an economically independent group of people having their own specific economy. The first and foremost characteristic of the tribal economy is the close

a. Pre-agriculture level of technology,

b. Stagnant or declining population,

c. Extremely low literacy, and

d. Subsistence level of economy.

5.2. Periodical Markets:-the soura tribal women areas, periodical markets and the system of barter exchange play a vital role in the economic life. These periodical markets were weekly, fortnightly, or biweekly and are widespread in the tribal areas of soura tribr, These periodical markets, locally known as Bazar, Hat, etc., generally serve the tribal villages within the radius of 5-15 KMs. and function on a specific place, at regular intervals of time. As a result soura tribe are get more benefit its improved income sources .

5.3.Interdependence The economic relationship among the tribes is often considered as one of interdependence while the spirit of competition is almost absent in the tribal economic life. The relationship between tribes, within tribes, or tribal people and non-tribal people are functionally interdependent. Vidyarthi and Rai(1976) observe that the economic functional interdependence is similar to the Jajmani system, found among the Hindu caste groups in most of the regions of the country. Under the Jajmani/sahukara system each caste group, within a village, is expected to give certain standardised service to the people of other castes. The family head served by an individual known as the Jajman, while the man who performs as Kamin of Jajman. Economic interdependence among the tribes has been observed in different tribal zones of the country in variety of ways

Community as a Cooperative Unit Community works as a cooperative unit in tribal societies and economic activities are carried out in collectively as a group. its relative isolation from outer world contributes to mutual dependence people sharing many social relationships. In fact, the economic activities of tribal people are embedded in their 


\section{International Advanced Research Journal in Science, Engineering and Technology \\ Impact Factor 7.105 Vol. 9, Issue 1, January 2022 \\ DOI: 10.17148/IARJSET.2022.9157}

neighbourhood, religion, kinship and political relations. In soura tribe some of part its believed that all are depend each other for their livelihood,

5.4.Simple Technology The development of an economy depends upon the level of its technological advancement. Generally, it is held that technological advancement leads to economic development. Technology, involves the use of tools and implements in utilisation of natural as well as human resources for productive purposes. The tools and implements used in the productive and distributive process of tribal economy are generally crude, simple and indigenously developed without the aid from outside. The simple technology used by most of the tribes in the country involves tenuous manual labour, and higher degree of wastage and difficulty, which is appropriate to their subsistence level of production, the soura tribe women are helped the men for farming,

5.5.Forest Based Economy Tribal economy :-Soura women are play a important role for collection of tribal product, the tribal economic is embedded in and revolves around the forest ecology. Not only the tribal economy, but also the culture and social organisation are interwoven with forests. Forests constitute the major natural resource base for tribal livelihood in all the tribal regions of the country. Tribals depend on forests for fulfilling their basic needs. The tribals harness the forest resources with the help of simple implements without much technological aid from the outer world. They collect edible roots, fruits, vegetables, flowers, honey, insects, fish, pigeons, hares, pigs, etc,. from the forests for their consumption. The forest dependence of the tribes in the country differs with their economic typology.

5.6.Economic Change in Tribal economies in India are in transitions. Their exposures to a number of exogenous factors contributed to change in them. They adapt to the modern economic forces, acquire economic new activities, adopt modern technology and means and are geared towards achieving the goal of development. There are a number of factors that can be attributed to change in the economic structure and functions of tribes in India. The chief among them are educational expansion, transportation and communication, Cooperatives and Commercial Banks. In addition to these the Government policy, programmes and development interventions have also contributed to economic changes.

\subsection{About Self help Group}

The soura tribe are stated business and other necessary activity through The Self Help Group (SHG) has developed from the poverty initiatives. SHGs bring together soura tribe women with common experiences planned socio economic development, through several Government programme are lead the SHG, have cognizable success in bringing women into main stream of decision making, family and financial oriented activities. In Gajapati district, many SHGs are 'linked' to banks for the delivery of micro credit. The government is focusing on their participation in rural development and Economic developmental activities with tribal women. SHGs have made important contributions to the economic development of tribal women family unit and the economic development of the financial system. SHGs plays a significant role in empowering tribal women by progressive their socioeconomic condition, decision making power and weakly/monthly money regular change capability structure. The Self Help generally refers to groups that involve people who have similar needs, and are operated on informal and non-profit basis. SHGs are member-based microfinance intermediaries inspired by external technical support that lie between informal financial market actors.

6.0.Impact of Government scheme Women Empowerment :- Through Govt. scheme like Odisha Livelihood Misson (OLM), Mission Jibeka, Odisha PVTG Empowerment \& Livelihood Improvement Programme (OPELIP),Odisha Tribal Empowerment Livelihood Programme (OTELP), Vana Dhana Vikash Kariyakarm (VDVK), Focussed Area Development Approach (FADP) Number of soura tribe women get income through selling all value addition products with best price, who are living below poverty line, will be reduced. By the help of SHG, poor village women will get better quality of life and livelihood, which will be helpful to increase the social and economic women empowerment. As a result, the future will be bright of these 1500 women and their families, life with dignity, gender equality, are bring the happy tribal women through above Programme.

6.1.Revolving Fund Service (RFS):- By the help of SHG, poor village women will get better quality of life and livelihood, which will be helpful to increase the socially and economically women empowerment. Under this fund the SHG member are prepare a Micro Investment plan, Business Development Plan and used the fund like their daily need, the proposed of this RFS Fund for business, farming, family function, children education, health etc.

Through this programme support Govt. tray to market linkage all SHG production and ensure sealing good price, given Technical \& handholding support through Capacity Building Training Programme. For improve skill their knowledge, new innovation are implemented Programme area.

\subsection{Kitchen Garden/ Nutrition Garden:-}

Through this progrmme are covered 2435 soura tribe SHG under Training progrmme on Kitchen Garden and its benefit, under kitchen garden program Govt. distribute seed kit of every household under SCA to TSSA and other 


\section{International Advanced Research Journal in Science, Engineering and Technology \\ Impact Factor 7.105 Vol. 9, Issue 1, January 2022 \\ DOI: 10.17148/IARJSET.2022.9157}

scheme a high bread quality seed fro used it kitchen garden programme. In local language its called Mo Badi Bagicha. The objective this programme reduced malnutrition of pregnant women and adolescence girl child.

As author study under both kitchen garden and Nutrition Garden its focused a health life, and fresh vegetable used in dally cooking . as a result this programme also help financial support.

The specific objectives are as under:

- $\quad$ To create awareness about kitchen gardening.

- $\quad$ To improve skills for growing fresh and safe vegetables without use of any pesticide.

- To provide complete set of production technology including quality seedlings and potted plants of summer and winter vegetables

\section{Increasing Participation in Democratic Institutions through Panchayat Raj}

In the past decade good governance and decentralization have become two of the main development pillars, relied on by both international development agencies and the authorities in developing countries in the quest for successful development. In India steps have been taken to increase the participation of the weaker sections of society in new arrangements for decentralized local decision-making through rules of reservation. This article discloses the potential and the pitfalls of increasing participation through decentralization by analyzing the Indian Panchayat Raj system. It is shown how technocratic regulations are not sufficient to ensure genuine empowerment for all in democratic decisionmaking.

Institution Delivery :-

Now a day tribal women are motivated for hospitality for delivery during pregnancy the scheme like Janani Suraksha Yojana (JSY) is a safe motherhood intervention under the National Rural Health Mission (NRHM) now tribal women motivated to go to instruction delivery as a good health,

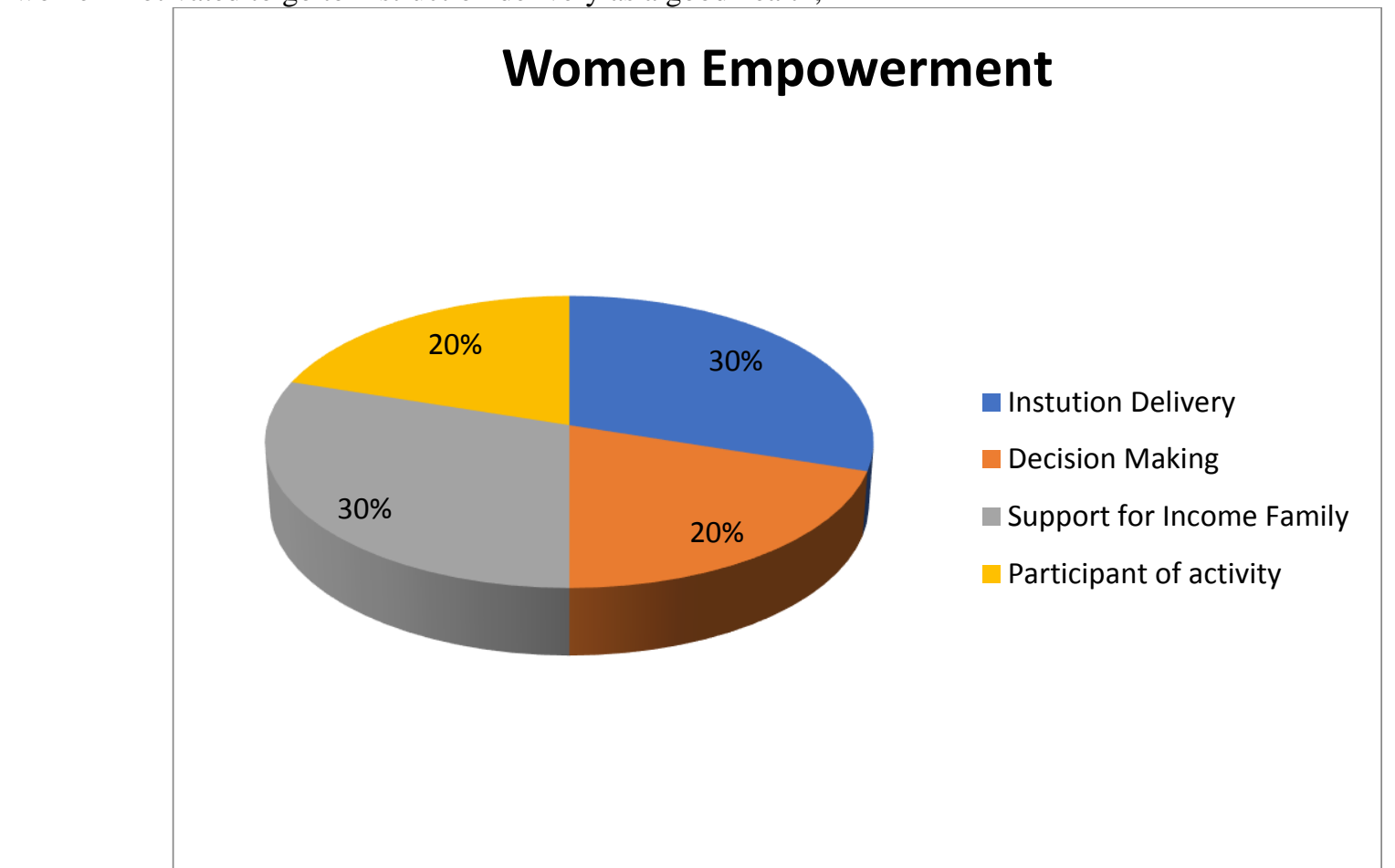

Case study -2

Raibada village are fully covered by forest, hear 3 number of SHG that is name Maa Laxmi , after Odisha Tribal Empowerment \& Livelihood Programme, this SHG get Rs 80000, this Group stated a leaf stitching machine, some member collect seali leaf in the forest and other member starting leaf plat making through this tailoring machine, now they all selling leaf plate nearest market also Andrhapradesh state .

\section{CONCLUSION}

As Odisha Government women empowerment programme, through this programme soura tribe women get some beniffited the district of Gajapati, Ganjam, and Rayagada also , Government allowed different scheme, programme is a flagship programme of Government this programme tray to improved all round of development of tribal community 


\section{International Advanced Research Journal in Science, Engineering and Technology \\ Impact Factor $7.105 \div$ Vol. 9, Issue 1, January 2022 \\ DOI: 10.17148/IARJSET.2022.9157}

and enbling them to enchance their food security, increase their incomes, Government stated SHG, group, Mission shakti , Handholding support of women for improved their income,

Its observed that soura tribe improved their economical income and adopt the new technology in the agriculture field, and same as women of soura tribe are income money through creation of group.

\section{REFERENCES :-}

Saora Tales and Songs, Edited by Dr Mahendra Kumar Mishra, Published by Sahitya Akademi, New Delhi. 2005,2018

1. ^ "ST-14 Scheduled Tribe Population By Religious Community". Census of India. Ministry of Home Affairs, India. Retrieved 15 October 2017.

2. ^ Reedy, P. Adinarayana (2004). Education of Tribal Women: A Comparative Study. Anmol Publications. ISBN 81-261-1831-8.

3. ^ Piers Vitebsky. Dialogues with the dead. Natural History Magazine, Inc. March 1997

4. ^ von Fürer-Haimendorf, Christoph (1982). Tribes of India: The Struggle for Survival. University of California Press. pp. 77-78. ISBN 978-0-52004-315-2.

5. ^ Piers Vitebsky, Living Without the Dead: Loss and Redemption in a Jungle

6. Cosmos, The University of Chicago Press, Chicago, 2017.[1]

7. ^ "Padala Bhudevi receives Nari Shakti Puraskar". Devdiscourse. Retrieved 4 April 2020.

8. Women and empowerment in Contemporary india bt Brati Biswas and Ranjan Koul

9. Empowerment of Tribal Women by DR.anany Har

10. Status and Empowerment of Tribal Women in Tripura Dr.Mrs. Krishna Nath Bhomik 